\title{
Discussion: Reduced partial factors in UK standards for assessment of bridges and structures
}

Christopher R. Hendy FREng, MA (Cantab), CEng, FICE

Atkins, Epsom, UK (corresponding author: chris.hendy@atkinsglobal.com)

Louisa S. Man MEng, CEng, MICE

Atkins, Epsom, UK

Rachel P. Mitchell MEng, CEng, MICE

Atkins, Epsom, UK
Hideo Takano BEng, ACGI, CEng, MICE, MCIHT

Highways England, Guildford, UK

Alasdair N. Beal BSC, CEng, FICE, FIStructE

Thomasons Ltd, Leeds, UK

\section{Contribution by A. N. Beal}

Regarding the paper by Hendy et al. (2018), this discusser would like to raise the following points.

(a) The authors' summary of BS EN 1990:2002 annex C does not mention the following important statement (section C3).

(2) In principle numerical values for partial factors and $\Psi$ factors can be determined in either of two ways:

(a) On the basis of calibration to a long experience of building tradition.

NOTE For most of the partial factors and the $\Psi$ factors proposed in the currently available Eurocodes this is the leading Principle.

(b) On the basis of statistical evaluation... (BSI, 2002: p. 8)

Eurocode safety factors are based on experience and past practice, not statistical calculations.

(b) Researchers may often use $1 \times 10^{-6}$ as a target annual failure probability but this is not generally accepted as a reasonable safety level within the industry. Practising engineers rarely discuss reliability calculations and they are not used in current design codes.

(c) Current bridge loadings bear no relationship (statistical or otherwise) to loadings 50 or 120 years ago - and loadings in 50 or 120 years' time are unlikely to be the same as today. Using current loadings to calculate failure probabilities for 'design lives' extending 50 or 120 years into the future seems very abstract.

(d) The figures in Table 4 for concrete strength are reasonable for construction test cubes but concrete in a structure is usually weaker and more variable because of compaction, curing and cracking. Similarly, the figures for steel suit original test samples but in real structures, corrosion, fatigue or accidental damage can reduce strength.

(e) One failure probability for all parts of a structure is convenient for calculations but does not consider the consequences of failure. For example, consider a suspension bridge - deck plate failure is not serious, suspension hanger failure may be worse, main cable failure is very serious and a main tower failure is catastrophic. Other structures are similar; the consequences of failure are more serious for some parts than others, so a uniform failure probability is not good engineering. Failure consequences are usually worst for members carrying mainly dead load, so these need a lower failure probability. This affects section 5.5 of the authors' paper.

( $f$ ) Most structural collapses are caused by loss of strength or excessive loading. When reviewing bridge collapses since 1950 , did the authors find any caused by statistical variation of ordinary loadings and material strengths?

( $g$ ) In the Barton High Level Bridge, would failure of the overstressed bracing be ductile, buckling or brittle? Was the construction quality and condition of the relevant parts assessed?

(h) When assessing an existing structure, the critical issues are as follows.

(i) The condition of relevant parts of the structure

(ii) Would failure be ductile or brittle?

(iii) What are the consequences of failure of the overstressed element?

(iv) Is full design loading on the structure likely?

Probability calculations are no substitute for an engineering assessment that carefully addresses these questions.

\section{Authors' reply}

It is agreed that the partial factors in the Eurocodes have mostly not been determined directly to achieve set reliability levels but, instead, many replicate the results of existing national standards that are deemed to provide adequate reliability. BS 5400 and in 
turn the Design Manual for Roads and Bridges (DMRB) (HA, 2017), which is relevant to UK assessments, does not explicitly state the reliability level achieved. However, it is also noted that most of the new rules being written for the next generation of Eurocodes are setting characteristic strengths and partial factors in line with a reliability index of $3 \cdot 8$.

In the authors' work, calibration was carried out to derive the reliability index for a given set of DMRB partial factors and distribution models, and it was found that these are comparable to the $f i b$ Model Code 2010 values (fib, 2013), which were therefore taken as the baseline. Furthermore, it was found that the $f i b$ Model Code 2010 values achieve an industry-acceptable probability of fatality by structural failure over all consequence classes and are therefore suitable for use.

The failure probability is accepted by researchers within the field of reliability. It is used in ISO 2394:2015 (ISO, 2015) and the fib Model Code 2010 and is the basis for the safety index values used in determining the partial factor reductions across all consequence classes. It is acknowledged that practising engineers will not necessarily understand reliability calculations, or how partial factors are statistically derived. However, it was the intention of this work to provide methods that can be applied without this detailed understanding, either by applying the individual partial factor reductions or applying a uniform partial factor reduction, the values for which are conservative. This is providing the assessment does not fall outside the limits of applicability stated in the paper.

It should be noted that the Highways Agency (now Highways England) document BD 79/06 (HA, 2006) permits the use of reliability-based methods for assessment but gives little guidance on acceptable probabilities of failure. The paper was initially commissioned to provide additional guidance.

Regarding the discusser's third point about bridge loading, the authors' approach matches how the current design (and assessment) characteristic loads have been determined, as these are suitable for 120-year design lives. It is agreed that future actions that are subject to systematic change, particularly traffic loads that may be directly controllable through connected autonomous vehicles rather than probabilistic, are difficult to predict.

The coefficients of variation in Table 4 are only part of the composition of the material factor. The variation in section dimensions and resistance model accuracy must also be included. When these are also included, the partial factor for concrete in compression comes out extremely close to 1.5 when the design target reliability is used, so the approach is entirely consistent with current design practice. The material partial factor is also not intended to account for significant section loss for corrosion or the presence of propagated fatigue cracks. In the case of corrosion, direct allowance needs to be made for such deterioration either by using reduced sectional area or by 'condition factors', which already exist in the assessment codes.

The authors agree with the discusser's point regarding failure probability, hence why different consequence classes and partial factors can be used for different details if required. The paper conservatively excluded long-span bridges, for which the potential number of casualties pushes up the target reliability. The full study included a decision tree for determining the consequence class and therefore the cost of safety measures based on aspects such as failure mode, structural redundancy and sustainability considerations, although this was not discussed in the paper. This would distinguish the treatment of a deck plate from a suspension cable.

Bad detailing is another principal cause, and failure is usually caused by a combination of factors such as bad detailing and loss of strength. There was insufficient information to determine whether any failures were caused solely by excessive statistical variation of loadings or strengths.

In isolation, failure of the bracing would be by buckling and not ductile. However, adjacent components in the real structure provided strain control to the bracing once buckling started and hence there was some ductility in the overall structure. However, there was still inadequate strength to meet full design requirements. Construction quality and condition formed part of the assessment for the reasons noted above.

The authors also agree with the discusser's final point; the critical issues are complementary, although item (iv) is itself suggesting the potential for probabilistic assessment and, in many bridges, bridge-specific assessment live loads are derived for precisely this reason.

\section{REFERENCES}

BSI (2002) BS EN 1990:2002: Eurocode 0: Basis of structural design. BSI, London, UK.

fib (Fédération Internationale du Béton) (2013) Model Code for Concrete Structures 2010. Ernst \& Sohn, Berlin, Germany. HA (Highways Agency) (2006) DMRB Volume 3 Section 4 Part 18 (BD 79/06): Highway Structures: Inspection and Maintenance. Assessment. Management of Sub-standard Highway Structures. HA, London, UK.

HA (2017) Design Manual for Roads and Bridges. HA, Guildford, UK. See http://www.standardsforhighways.co.uk/ha/standards/dmrb/ (accessed 28/08/2017).

Hendy CR, Man LS, Mitchell RP and Takano H (2018) Reduced partial factors in UK standards for assessment of bridges and structures. Proceedings of the Institution of Civil Engineers - Bridge Engineering 171(1): 3-12, https://doi.org/10.1680/jbren.17.00008.

ISO (International Organization of Standardization) (2015) ISO 2394:2015 - General principles on reliability for structures. ISO, Geneva, Switzerland. 